\title{
DOIS LADOS DO QUADRANTE: PAISAGEM E ARTE RUPESTRE DO SÍTIO JAMBREIRO, ALTO JEQUITINHONHA, MINAS GERAIS
}

\author{
Marcelo Fagundes* \\ Wellington Greco**
}

RESUMO: O sítio Jambreiro é um abrigo sob rocha implantada na bacia do rio Araçuaí, nordeste de Minas Gerais, em terra do município de Felício dos Santos. Trata-se de um lugar ocupado em longa duração e dadas às suas características geomorfológicas, foi identificado como sítio de passagem, com base nas análises regionais com enfoque no conceito de paisagem. 0 principal repertório cultural do sítio é a arte rupestre e este artigo trata acerca de um dos painéis do sítio (painel 03), confeccionado no teto do abrigo. Teórico e metodologicamente tem-se pensado os painéis como uma estrutura, um todo, que deve ser observado para além de suas camadas de confecção. Logo, sob um recorte metodológico, nos deteremos às pinturas, focando no estudo de suas características formais e buscando o entendimento de como foram produzidas por meio de um pensamento cuja estrutura de organização poderia ser, a priori, deduzida, enquanto projeto do trabalho humano.

Palavras-chave: Arte Rupestre; Paisagem; Estrutura; Bacia do Araçuaí; Serra Negra.

ABSTRACT: The Jambreiro archaeological site is a rock shelter located in the Araçuaí river basin, northeast of Minas Gerais, in the municipality of Felício dos Santos. It is a place occupied for a long term and given its geomorphological characteristics, it was identified as a crossing point site, based on the regional analyzes focusing on the landscape concept. The main cultural repertoire of the site is rock art and this article deals with one of the panels of the site (panel 03), made in the ceiling of the shelter. Theoretically and methodologically the panels have been thought of as a structure, a whole that must be observed beyond their layers of production. Therefore, under a methodological scope, we will focus on the paintings, focusing on the study of their formal characteristics and seeking to understand how they were produced through a thought whose organizational structure could be, a priori, deduced as a project of human work.

Keywords: Rock Art; Landscape; Structure; Araçuaí River Basin; Serra Negra. 


\section{Apresentação}

O sítio Jambreiro é um abrigo sob rocha quartzítica, localizado no município de Felício dos Santos, Alto Vale do Araçuaí, Minas Gerais, mais precisamente no sopé da serra homônima, um importante divisor de águas regional. Seu repertório cultural mais evidente são os painéis rupestres, distribuídos pelos três salões que compõem o abrigo. Apesar de existir um pacote sedimentar favorável às intervenções, por enquanto a equipe focou exclusivamente no estudo da arte. Em superfície algumas peças em quartzo hialino foram evidenciadas (lascas pequenas e refugos do processo de lascamento).

O sítio, apesar do aparente isolamento, faz parte de uma área com uma densidade considerada de abrigos pintados, muitos deles que denominamos de sítios de passagem (Fagundes, 2016). Os sítios de passagem estão implantados na alta vertente, em áreas de quebra de topografia, muito próximo a caminhos que possibilitam até hoje a comunicação entre lados opostos das diferentes serras que constituem o ambiente regional, entre o Cerrado (na bacia do Jequitinhonha) e a Mata Atlântica (na bacia do Doce).

Jambreiro é um destes sítios, em alta vertente, próximo a um caminho tradicional de passagem pelas serras do Jambreiro e Matão, dando acesso para sul/sudoeste em direção a outra face da serra e à planície da margem esquerda do rio Araçuaí, principal afluente do rio Jequitinhonha. Atualmente o caminho é utilizado pelas comunidades para a coleta de espécies vegetais (abundantes nas matas locais), para caça ou como comunicação entre povoados.

Além dele, quinze abrigos confirmam a ocupação pré-colonial da face nordeste de um dos marcadores paisagísticos mais importantes regionalmente: a Chapada do Couto (ou Serra do Gavião), importante área de ocupação pré-colonial e parte da rota norte de acesso ao distrito diamantino a partir do século XVIII, hoje grande parte destas terras pertencem ao Parque Estadual do Rio Preto.

O sítio, deste modo, é componente do que temos definido como Complexo Arqueológico de Felício dos Santos, integrado à Área Arqueológica de Serra Negra que está constituída por outros três complexos: Campo das Flores, Serra do Ambrósio e Três Fronteiras. De acordo com Fagundes (2013: 68) se entende como complexo arqueológico uma assembleia de sítios arqueológicos que apresentam características de implantação e repertório cultural semelhantes, assentados em um mesmo domínio biogeográfico. Portanto, são lugares, considerados não como um simples conjunto de formas e objetos específicos, mas sendo compreendidos como modo de reprodução, ou seja, uma estrutura simbólica e prática de (re) organização, particular, de objetos e formas específicas. São pontos estruturados e organizados, por meio de locais (mapas mentais) de referência, conhecidos e reconhecidos, explorados, significados e constantemente ressignificados. São valorados de acordo com as estruturas sócio-simbólicas onde são satisfeitas diversas necessidades humanas: biológicas ou espirituais; materiais e imateriais; reais ou mágicas etc.

Um somatório de complexos (lugares) forma uma Área Arqueológica que, além de compartilhar características semelhantes, possui indicadores de uma rede de trânsito entre o grupo (ou mesmo grupo) que divide um determinado território. 
Para este artigo o objetivo principal é apresentar o sítio Jambreiro e seu repertório cultural, destacando conceitos metodológicos e teóricos que temos pensado para a área e discutindo temas caros à pesquisa em Arqueologia. Assim, sob um recorte metodológico, nos deteremos às pinturas, focando no estudo de suas características formais e buscando o entendimento de como foram produzidas por meio de um pensamento, cuja estrutura de organização poderia ser, a priori, deduzida, enquanto projeto do trabalho humano.

\section{Características Geoambientais e de Implantação do Sítio Jambreiro}

Desde 2010 a Área Arqueológica de Serra Negra tem sido o foco de pesquisas desenvolvidas pelo Laboratório de Arqueologia e Estudo da Paisagem (LAEP/CeGeo/UFVJM). Localizada a nordeste de Minas Gerais, abrange cinco municípios mineiros do Alto Vale do Araçuaí: Itamarandiba, Rio Vermelho, Senador Modestino Gonçalves, São Gonçalo do Rio Preto e Felício dos Santos (Fagundes, 2013, 2016) (Figura 1).

Geologicamente está inserida na face leste da Serra do Espinhaço Meridional, assentada nos domínios da Província de Mantiqueira, entre o Cráton do São Francisco e a Faixa Araçuaí, tendo seu relevo modelado por rochas da unidade Super Grupo Espinhaço. Em toda a área, as elevadas serras alinhadas no sentido NW-SE são marcadas pelos quartzitos, que se diversificam em formações de abrigos, lapas e matacões onde se encontram os sítios arqueológicos (Knegt, 2015). Entre os situados em maior elevação, Jambreiro se localiza a $1.185 \mathrm{~m}$ de altitude.

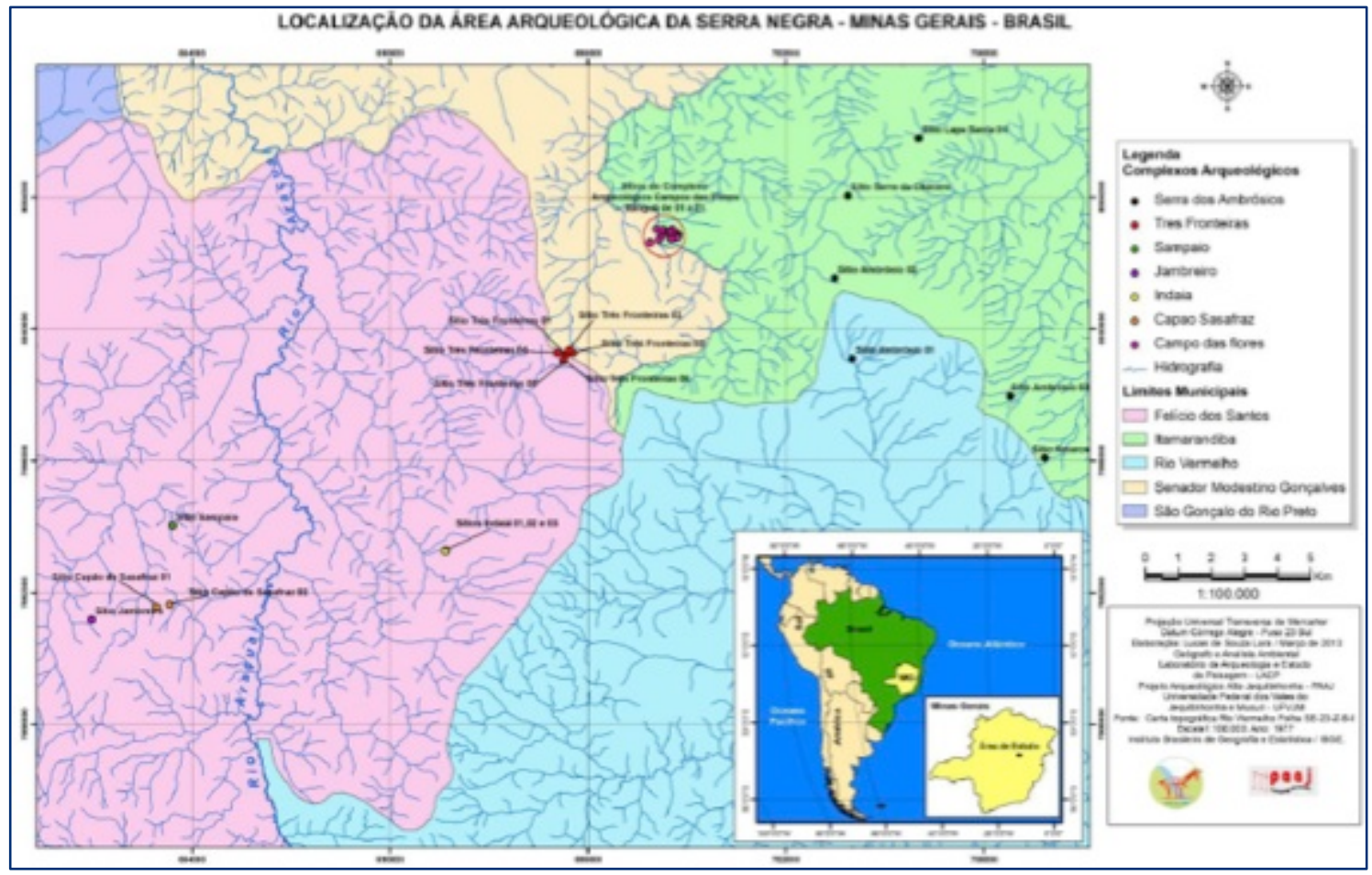

Figura 1: Mapa de localização da Área Arqueológica de Serra Negra. Fonte: Fagundes, 2013. 
Em termos hidrográficos, a Área Arqueológica de Serra Negra está inserida na Bacia Federal do Jequitinhonha (grande parte) e parcialmente do rio Doce, sendo o rio Araçuaí, tributário do Jequitinhonha, o curso d'água mais expressivo existente em seus limites. Com cobertura vegetal variada, pode-se considerar a área um ecótono, onde espécies característica do Cerrado (e suas várias feições fitoecológicas) e da Mata Atlântica podem ser identificadas (Fagundes, 2016).

O Jambreiro se caracteriza por ser um sítio implantado em uma área de campo de altitude, contudo seu entorno, sobretudo nos patamares mais baixos, é marcado pela forte presença da Floresta Estacional Semidecidual (Figuras 2 e 3).

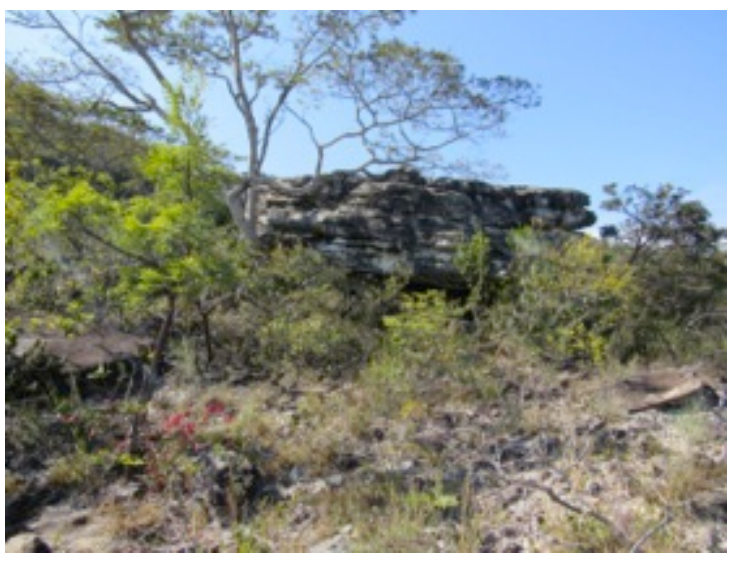

Figura 2: Visão geral do entorno imediato do sítio Jambreiro, destaque para a vegetação de campo de altitude. LAEP, 2017.

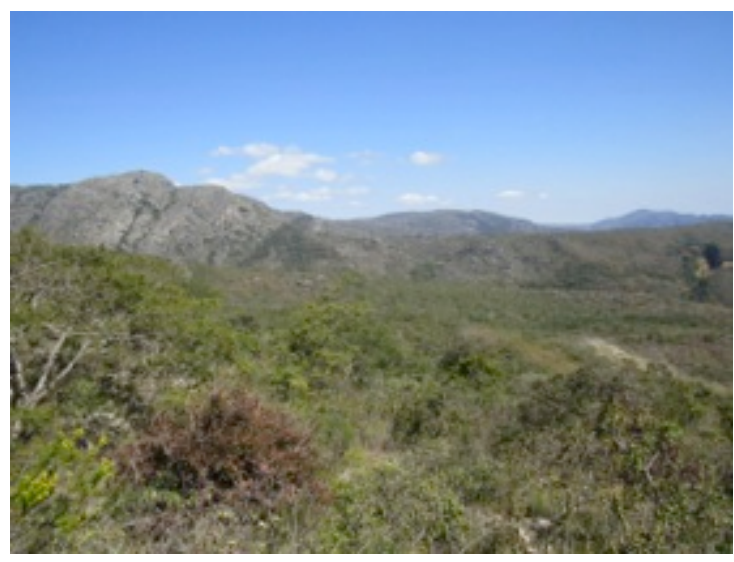

Figura 3: Visão geral do entorno do sítio, com destaque a serra do Matão ao fundo, área onde predomina a Floresta Estacional Semidecidual. LAEP, 2017.

Como dito, o Jambreiro é um abrigo sob rocha quartzítica, em alta vertente, implantado no sopé da serra homônima a $1.185 \mathrm{~m}$ acima do mar. Seu entorno imediato está constituído por campo de altitude, com vegetação mais densa no entorno da serra a sudoeste. Há várias nascentes muito próximas ao abrigo, garantindo fluxo de água frequente, o mais próximo ao sul, distante $50 \mathrm{~m}$ do abrigo, uma das nascentes formadoras do rio Santana (afluente da margem direita do Araçuaí), localizado a oeste do sítio. Todo o entorno é plano, uma vez que está em um dos vários patamares que seguem a partir da baixa vertente até o topo da serra do Jambreiro (Figura 4).

O acesso ao sítio é moderado, mesmo com a presença de caminho de uso contínuo que, segundo moradores locais, é de criação imemorável. Assim, não é possível chegar com veículos, sendo que a caminhada se inicia a $756 \mathrm{~m}$, subindo até os $1.185 \mathrm{~m}$ acima do nível do mar, onde está implantado o Jambreiro percorrendo-se, portanto, aproximadamente 2 horas de trilha.

A visada a partir do sítio arqueológico é magnífica. Para sul ganha destaque a Chapada do Couto, um braço do Espinhaço, rota das tropas que abasteciam o distrito diamantino, como já destacado neste texto. Ao norte todo o vale do rio Santana tem visão privilegiada, uma rota natural em direção aos vales do Araçuaí e Jequitinhonha (Figura 5). 


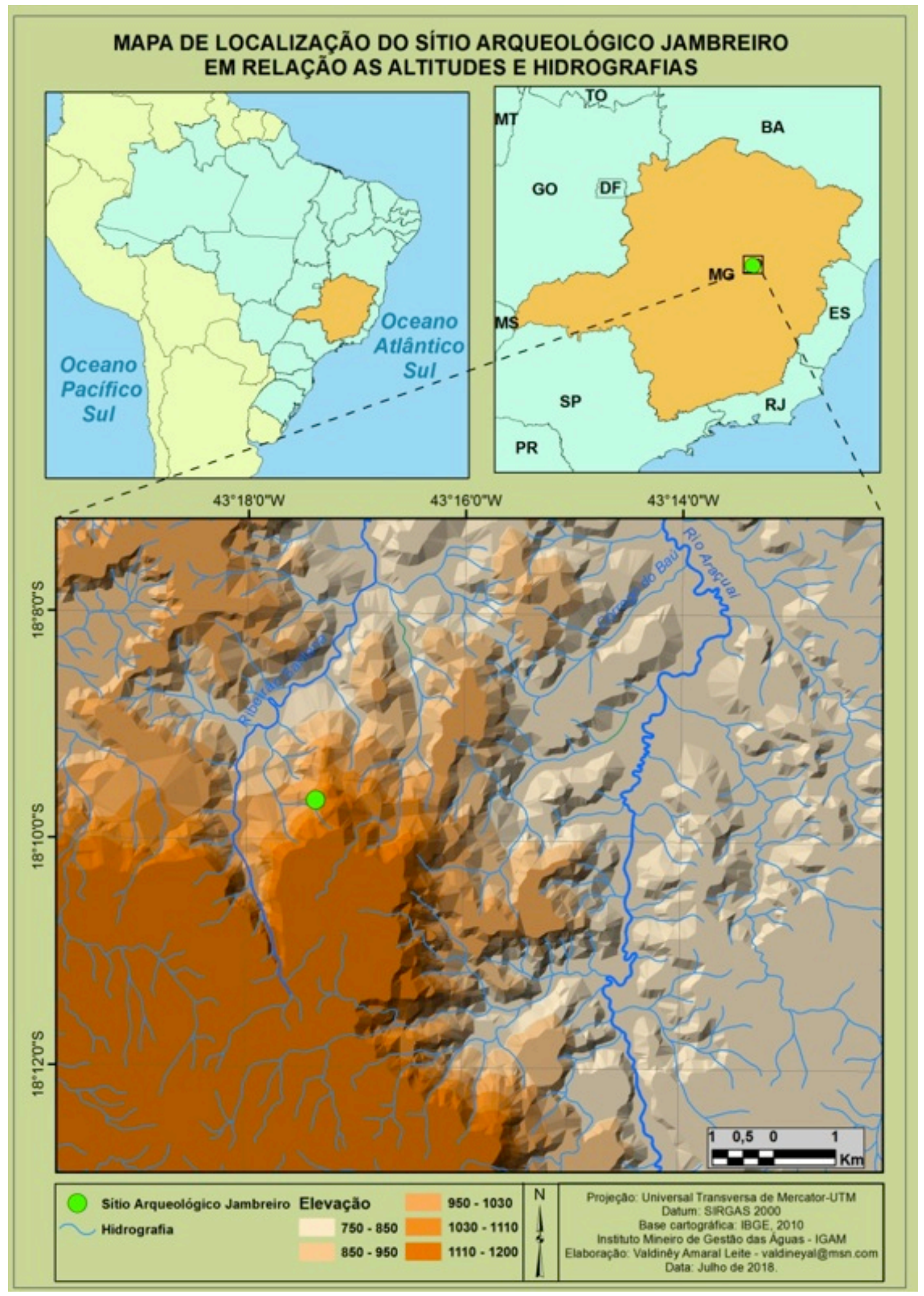

Figura 4: Localização do sítio Jambreiro. Fonte: IBGE, 2010. Elaboração: Leite, 2018. 
Para o oeste observa-se a serra do Matão e a grande diversidade florística que compõe o caminho até a serra (Figura 6). Para leste a visão a partir do sítio é prejudicada, mas caminhando cerca de $500 \mathrm{~m}$ pode-se ter acesso a um conjunto de serras onde outros sítios estão implantados, em outra rota em direção ao alto vale do Araçuaí.

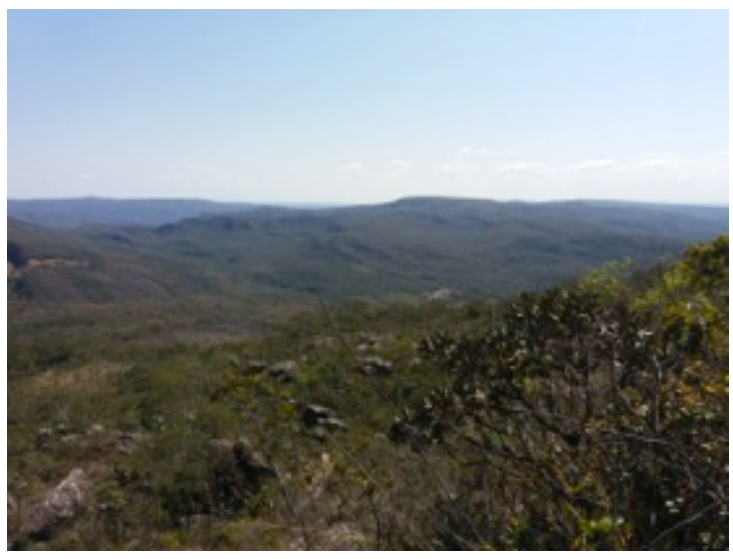

Figura 5: Vista do vale do rio Santana, a parte da face norte do sítio. Fagundes, 2017.

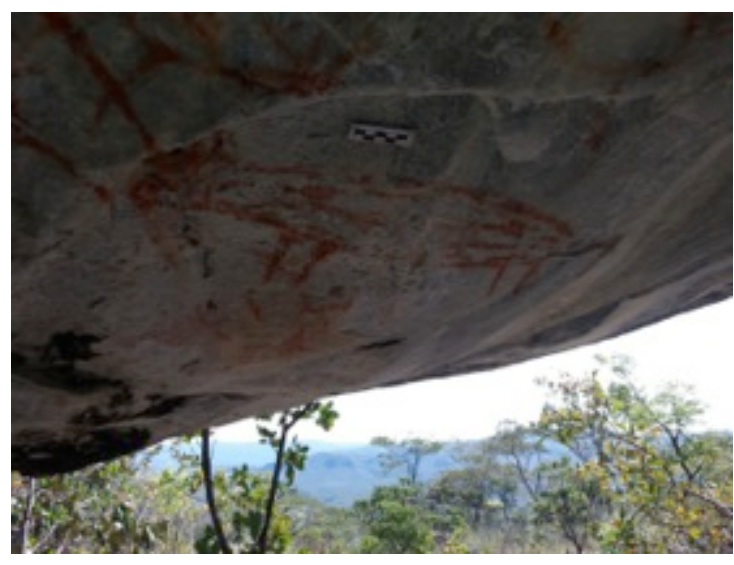

Figura 6: Visada a partir do interior do abrigo em direção oeste, para Serra do Matão. Fagundes, 2017.

Assim, do patamar onde se encontra implantado o sítio, pode-se avistar a imensidão de paisagens, compostas basicamente por serras e caminhos. Trata-se de uma característica importante, de longa duração, que demonstra a dinâmica regional do próprio uso e apropriação dos lugares. Os sítios são, nesta perspectiva, pontos de parada em longa duração, ocupados e reocupados ao longo do tempo, muito do que Schangler (1992) denominou de lugares persistentes.

O Jambreiro apresenta características peculiares e repertório que permitiram sua ocupação: (a) terreno plano no sítio e no entorno, em um dos vários patamares de acesso ao topo da serra; (b) espaço protegido contra sol, chuva, ventos etc.; (c) recursos hídricos constantes no entorno imediato; (d) disponibilidade de matérias-primas para as atividades sócio-cotidianas; (e) disponibilidade de diferentes plantas frutíferas, responsáveis até os dias de hoje por incursões de pessoas na busca de espécies típicas do cerrado etc.

O interior do abrigo é plano (levemente escalonado para o norte), constituído por três salões pequenos, em forma de ferradura, com frente voltada para nordeste (a partir do painel 01). Mas há ampla visão tanto no nordeste, quanto norte e noroeste. A altura média do teto nos salões é de 1,50 m. Há uma vegetação densa em todo o redor do abrigo (como uma cerca), demarcando muito bem a linha de chuva.

Apesar de ser um abrigo pequeno (cerca de $30 \mathrm{~m}^{2}$ ), é um sítio muito pintado, a maioria dos grafismos no teto do abrigo, mas também há nas paredes. A temática dos grafismos é aquela já descrita pela Tradição Planalto (Prous, 1992), com presença marcante de cervídeos e predominância de figuras monocromáticas, a grande maioria em vermelho (Figuras 7 e 8). 


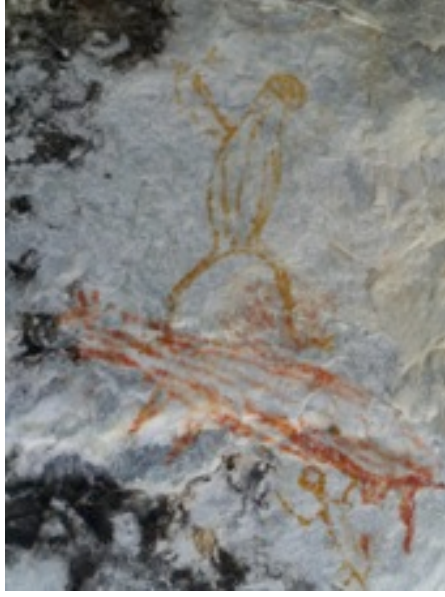

Figura 7: Fragmento de painel (teto). Fagundes, 2017

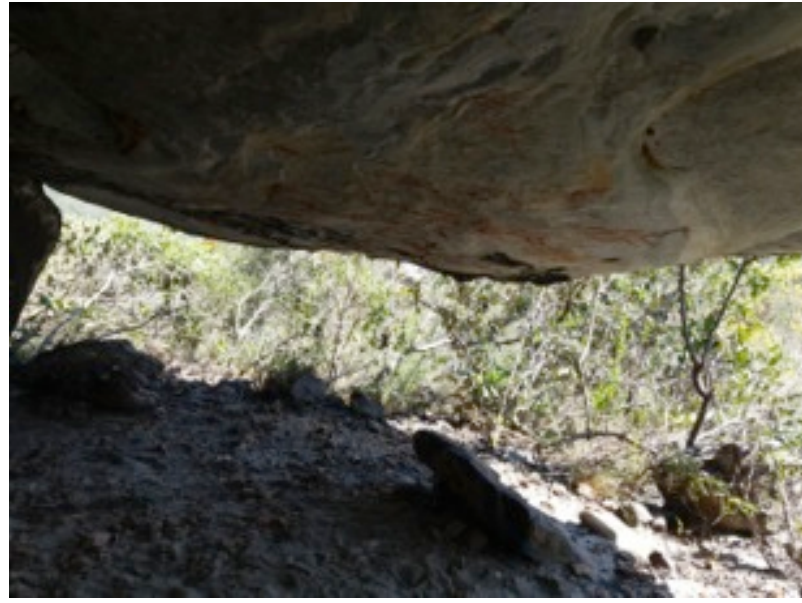

Figura 8: Destaque para painel do teto, face norte do abrigo. Fagundes, 2017

\section{Paisagem Enquanto Conceito}

Muitos autores têm discutido o que é paisagem e, portanto, acreditamos que se faz desnecessária uma ampla discussão sobre o conceito geográfico tão utilizado por arqueólogos nos últimos tempos (Zvelebil, 1997; Acuto, 1999; Anchuetz, 2001; Troncoso, 2001). Logo, preferimos discutir o que a paisagem não é.

Enquanto conceito, paisagem não pode ser entendida como caracterização geoambiental de uma área onde estão inseridos os sítios arqueológicos. Não se trata dizer sobre as serras, os rios, a cobertura vegetal ou acerca dos paleoambientes. O conceito vai muito além e, talvez por isso, seja tão caro aos estudos arqueológicos.

Com isso, de forma alguma não se pretende reduzir a importância do entendimento das características ambientais dos contextos que estudamos, um dos alicerces da pesquisa sob nosso ponto de vista. Afirmamos que são coisas distintas.

Logo, é fundamental entender onde e como os sítios estão sendo implantados, sobretudo com a realização de pesquisas com enfoques ecológicos e análises de geoprocessamento, inclusive tendo como uma das metas o estabelecimento de modelos preditivos de escolhas de implantação, de rotas, de distribuição espacial dos assentamentos etc. Contudo, acreditamos que estas possibilidades devem ser entendidas como ferramentas e não como um fim aos estudos arqueológicos.

Partimos do pressuposto que a constituição do que entendemos como paisagem (das paisagens) se dá a partir das interações e da dinâmica social, envolvendo questões de ordem simbólica, ideológica e a própria cosmovisão, portanto, seus portadores a interpretam, dão sentido e sentimentos ao lugar a que habitam.

Depende de percepção, de visão de mundo (e da vida) e não necessariamente da modificação/ transformação, apesar de que estas ações também estejam intimamente ligadas ao modo que 
as pessoas veem, classificam e percebem o mundo à sua volta. A paisagem se constitui a partir das inter-relações entre pessoas, objetos, formas e percepções, a partir de processos históricos, ambientais e contextuais.

Os lugares constitutivos de uma paisagem são experimentados pelo (s) sujeito (s) de acordo com as ideias, símbolos e ideologias do mundo em que ele faz parte (Zvelebil, 1997).

Assim, ao se tratar da paisagem (enquanto conceito) entendemos que é uma somatória de lugares em que pessoas dão sentido a vida, interpretam a si mesmas, as coisas e o mundo. São lugares de entendimento e ressignificação, por isso são sempre dinâmicas, sistêmicas/ contextuais e históricas. O mundo que vemos hoje está constituído por camadas destas paisagens, que podem ser lidas e, consequentemente, interpretadas por meio das marcas/registros que são deixados em longa duração (Cosgrove, 1984).

Nesta pesquisa é deste modo que a paisagem é concebida e as interpretações a partir dela são realizadas, mesmo que, arqueologicamente, muitas destas marcas/registros possam se perder, muitas vezes dada a natureza da pesquisa em Arqueologia.

O sítio Jambreiro, sob este ponto de vista, é um sítio de passagem, ocupado e reocupado em longa duração (até o presente), trazendo em suas características de implantação e repertório, escolhas de diferentes humanos que ali pararam e deixaram suas marcas. $\mathrm{O}$ abrigo é um lugar para além de suas características morfológicas ou funcionais e, por mais que seu uso esteja vinculado a tal, não se ocupa qualquer lugar na paisagem, há questões/ restrições associadas ao universo simbólico e ontológico, que permite ou restringe os diferentes tipos, o tempo e a intensidade destes usos.

Por mais hipotética que seja nossa afirmação, lidamos com pessoas e, desta forma, tais prerrogativas não podem ser descartadas de nossas análises.

\section{Estrutura, Pensamento e Arte Rupestre - Teoria e Método}

As ações humanas estão amarradas a uma complexa teia de atributos e questões de cunho biológico, psicológico, cultural e social, que envolvem significados e significações que dão sentido aos gestos, falas, ações, em suma, às múltiplas faces da existência humana (individual e coletiva) em sua plenitude (Mauss, 1979). Tal intrincada realidade que envolve diversos agentes (percebidos como humanos, como humanizados, ou não) é causa, forma, matéria e destino dos modos como a humanidade se percebe e se insere no âmbito de sua própria criação. Produção e produtor coexistem em ação.

Em Antropologia Estrutural Dois, citando Durkheim (1900: 190), Lévi-Strauss (1993: 25) destaca que: "A estrutura mesmo se encontra no porvir... Ela se forma e se decompõe incessantemente; ela é a vida chegada a um certo grau de consolidação; e distingui-la da vida da qual ela deriva, ou da vida que ela determina, equivale a dissociar coisas inseparáveis".

Por isso, os agentes não foram entendidos como indivíduos independentes e desconexos entre si e entre eles e o mundo, mas como integrantes de uma realidade social, um todo maior: a 
sociedade. Coeso, mas não necessariamente coerente, o grupo social forma um sistema com leis e normas de significação que o define constantemente sob um discurso identitário, isso em e pela própria dinâmica que o movimenta e mantém. A arte rupestre é a elaboração de corpos também construídos e mantidos, ela é produção sob e, por conseguinte, de memória (não só do modo de fazer, mas dos objetivos, atributos, limitações e exigências que envolveram a atividade).

Assim, a arte rupestre foi entendida como produto de ação, sob um pensamento coletivo e individual. As pinturas foram consideradas parte desse processo que não se iniciou, nem se findou, no que foi escolhido para ser inscrito na superfície rochosa, mas orientou, limitou e significou as escolhas envolvidas em todo exercício de pintar. Desde o ensinamento da função das pinturas, a instrução da interpretação adequada, a escolha da matéria base para as tintas e do seu local de coleta, o comportamento durante e após as atividades e o ato de pintar, que tem as próprias pinturas como registro, antes, durante e após a materialização das formas na parede, a arte foi/é conteúdo discursivo. Antes de ser forma, ela já existia em conteúdo; antes de ser pintura, ela era discurso, que a definiu, enquanto pintura, enquanto produção, enquanto vestígio. É tênue a linha entre a materialidade e a imaterialidade.

Lévi-Strauss (1993: 137-138) destaca que:

Para o estruturalismo, esta oposição não existe: não há, de um lado, o abstrato e, de outro, o concreto. Forma e conteúdo são de mesma natureza, sujeitos à mesma análise. $O$ conteúdo tira sua realidade da estrutura, e o que se chama forma é a estruturação das estruturas locais que constituem o conteúdo.

Ainda de acordo com o antropólogo francês:

Só é estruturado o arranjo que preencha essas duas condições: ser um sistema, regido por uma coesão interna; e esta coesão, inacessível à observação de um sistema isolado, revelar-se no estudo das transformações, graças às quais encontram-se propriedades similares em sistemas aparentemente diferentes. Como escrevia Goethe: 'Todas as formas são semelhantes, e nenhuma é igual às outras, de tal modo que sua harmonização conduz a uma lei escondida (Lévi-Strauss, 1993: 26).

A procura por esta lei escondida é o maior objetivo deste trabalho. Por isso, em síntese, ele se deu em quatro momentos diferentes que, por vezes, não se sucederam, mas se complementaram, assim que se considerou necessário. São eles: (a) o estudo do referencial teórico-conceitual; (b) o registro do objeto de pesquisa; (c) a análise dos dados e (d) a escrita das considerações e reflexões.

Segundo Lévi-Strauss (1985: 233), "[...] o símbolo tira a sua significação do contexto, de sua relação com outros símbolos que, do mesmo modo, só ganham sentido em relação a ele". Assim, sua significação não existe, em si, no absoluto; ela é, somente, de posição, uma vez que: 
[...] os signos e os símbolos não podem desempenhar seu papel senão na medida em que pertençam a sistemas regidos por leis internas de implicação e de exclusão; e porque a característica de um sistema de signos é ser transformável, ou ainda, traduzível na linguagem de um outro sistema com a ajuda de substituições (Lévi-Strauss, 1993: 26).

Nesse sentido, é o estabelecimento de relações entre os termos que possibilita a significação, tanto do contexto como dos objetos (Lévi-Strauss, 1983). Não são apenas os traços e formas que são conscientemente elaborados, mas também o lugar e interações com os outros termos que também são cuidadosamente explorados.

Desde o início da pesquisa, o sítio foi entendido como um todo indivisível, que só existe de tal modo em virtude da existência de cada elemento que o constitui e o constrói. As dimensões físicas do abrigo, os aspectos das paredes, as cores das pinturas, as disposições das formas e vestígios foram todas considerados como imprescindíveis para a existência do todo, de seu sentido e valor.

Além do registro escrito, em cada oportunidade, todos os grafismos foram fotografados, com vista a uma análise mais detalhada de suas informações e a confirmação ou refutação das já observadas em campo. Todas as informações obtidas foram tabuladas em fichas de análise qualitativa e quantitativa, de modo a ser possível uma caracterização sistemática dos dados obtidos, com vistas a um entendimento do sítio enquanto um todo indivisível e coerente.

Em todas as atividades de campo, todos os grafismos foram detalhadamente analisados e fotografados (Figuras 9 e 10). As dimensões dos traços, a forma das figuras, a constituição dos preenchimentos, a integração no suporte rochoso e as relações entre as pinturas, se isoladas ou sobrepostas, tiveram atenção.

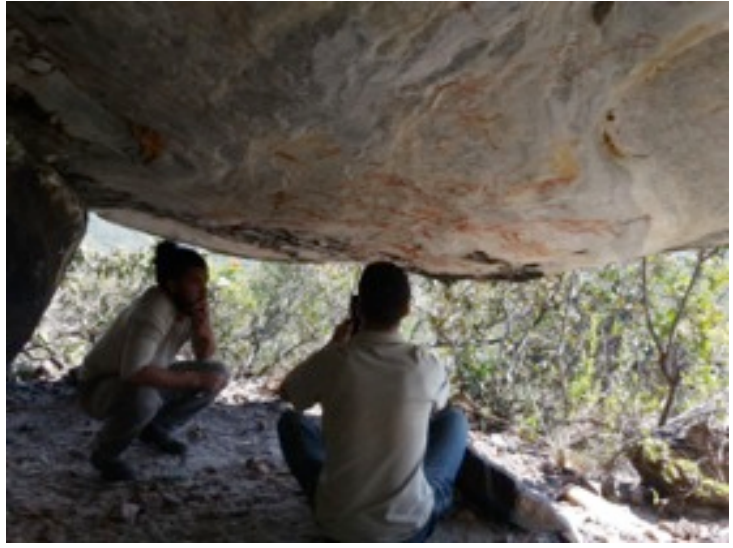

Figura 9: Trabalho de campo. LAEP, 2017.

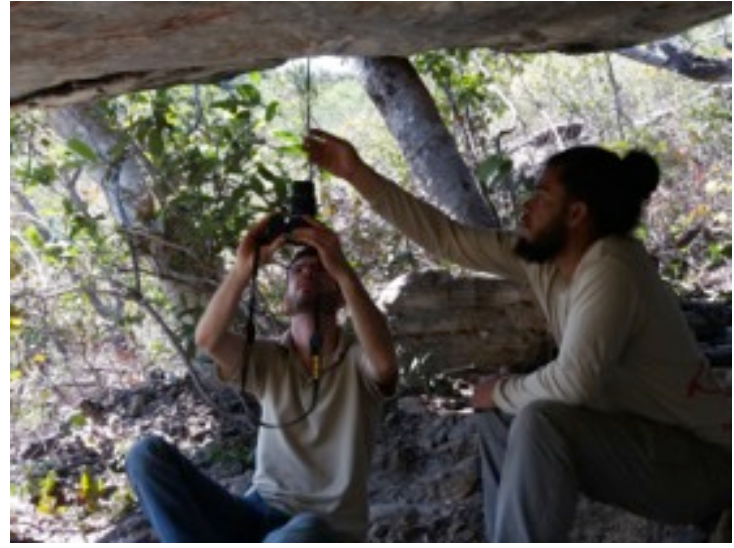

Figura 10: Trabalho de campo. LAEP, 2017.

Como Isnardis (2004) sublinha, a fotografia não equivale à experiência em campo, uma vez que se trata de um registro instantâneo de uma lente, limitado a uma perspectiva, a condições de luz, foco e ângulo específicos, que se tomado, exclusivamente, como objeto de análise, fornece um material extremamente limitado. Sutis alterações no relevo da parede do abrigo, sombras, ou o próprio foco do equipamento podem provocar distorções nas imagens, em proporções variadas, que tornam a fotografia um método e um material extremamente frágil e 
questionável. Contudo, é inviável a ida a campo, assim que se considera necessário, por diversos fatores, por isso, apesar do conhecimento das limitações e contrapontos, considerouse preciso o uso da fotografia como um registro do material.

Por meio do registro fotográfico, foi feito calque digital das figuras, visando um registro dos grafismos, para além da fotografia e das descrições feitas em campo. A fotografia foi tida como a base da análise, mas não foi considerada o único vetor de informação. Todos os calques tiveram por orientação, especialmente, os registros das observações feitas em campo.

\section{Quadros Rupestres: A Arte de Jambreiro}

Como dito, o Jambreiro é um abrigo com teto a uma altura média de 1,5 $\mathrm{m}$ em relação ao solo atual (Figura 11). Possui pinturas nas paredes, mas, neste texto, iremos tratar apenas dos 30 grafismos identificados no teto, sobretudo em virtude do processo de pesquisa, ainda em andamento.

Trata-se de um ensaio, por assim dizer, que busca entender as pinturas para além de sua individualidade, como um conjunto intrínseco, pensado como tal. Em resumo, as análises não se detiveram a cada pintura em específico, mas no processo de constituição do painel, sob o entendimento que há uma diversa proximidade entre sincronia e diacronia, que coexiste e codefinem.

Em termos morfológicos das pinturas, o painel 3 (teto) de Jambreiro possui zoomorfos e antropomorfos, ambos monocromáticos (em amarelo ou vermelho, este último na sua maioria). Entre os zoomorfos, maior grupo de grafismos, os quadrúpedes (tetrápodes) constituem quase a totalidade das pinturas. Como característico da região, os cervídeos são os que recebem maior destaque em números (Figura 11).

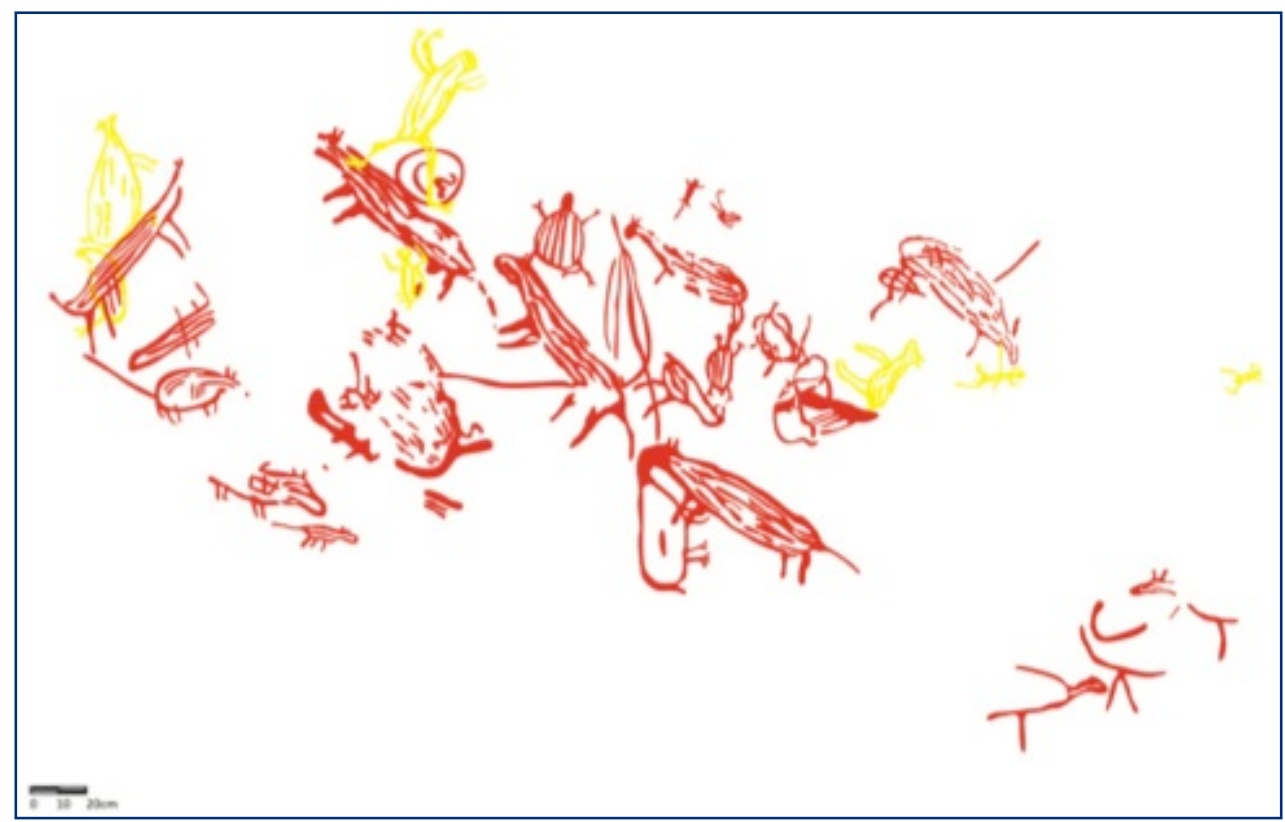

Figura 11: Calque digital do painel 03 do sítio Jambreiro. Greco, 2018. 
Durante as análises, a metodologia constituiu em dividir o painel em quatro partes e com o desenvolvimento das informações outras subdivisões poderiam ser delimitadas. Contudo, visando à síntese da discussão, considerou-se sensata a apresentação do painel no quadro final de porções estabelecidas. Os quatro quadrantes desenhados no início foram subdivididos, totalizando dezesseis quadros. Eles são o pano de fundo da análise e orientação da interpretação feita. As outras figuras geométricas criadas que os sobrepõe auxiliaram na descrição da análise realizada (Figura 12).

Por esse esquema de leitura, foi possível observar que sobrepostos ao painel, os quadros A1 e D4 ficam vazios. Além de estarem em extremidades opostas, são inversamente proporcionais, ocupando pontos de uma mesma linha se traçada perpendicularmente sobre o painel. Os quadros A2 e D2 também se encontram vazios, em situações parecidas com a anterior, ocupando uma mesma linha e distância em relação ao ponto zero.

As relações entre extremidades inversamente proporcionais e vazios também podem ser visualizadas nas áreas demarcadas pelos triângulos azuis. Visto como um plano cartesiano (em relação ao ponto zero), o triângulo azul ocupa a área mais distante no quadrante formado pela abscissa negativa e pela ordenada positiva (- +). Já o triângulo azul pontilhado também ocupa a porção mais distância do ponto zero, mas no quadrante formado pela coordenada $\mathrm{x}$ positiva $\mathrm{e}$ pela linha y negativa (+ -).

Sobre as pinturas, as em amarelo se concentram nos quadros B3, A3, B4, C2 e C1. Se traçada uma linha horizontal passando pelo centro do quadro formado pelo encontro das hipotenusas dos triângulos desenhados, B3, A3 e B4 são a porção inversa de C2 e C1. Ocupando os quadros de mesma distância do ponto zero, o primeiro conjunto se localiza no quadrante de abscissa e ordenada negativas (- -) e o outro de abscissa e ordenada positiva (++).

Tomando as áreas demarcadas pelos triângulos em rosa, a situação é, a priori, diferente, mas na mesma relação de dicotomia. O quadro B4 é única parte do triângulo rosa com figura e D2 é única do rosa pontilhado sem figura. Considerando o plano cartesiano formado, o triângulo rosa ocupa o quadrante constituído pelaabscissa e ordenada negativas. Sua porção vazia é a mais distante do ponto 0 da ordenada. Já o triângulo rosa pontilhado está delimitado na outra extremidade do plano, no quadrante de abscissa e ordenada positivas. Sua porção com desenhos também é a mais distante do ponto central do plano, ou dito de outra forma, sua porção vazia é a mais próxima do ponto zero da ordenada.

Tendo o centro do plano como foco, se sobre o ponto zero for traçado um $\mathrm{x}$, os antropomorfos ocuparam pontos de uma mesma linha. Já a outra linha do $x$ confeccionada passa sobre os cervídeos. Um cervídeo está com a cabeça desenhada na parte negativa da linha $x$ e a sua parte traseira está em ponto positivo da linha y, também afastado do zero. O outro cervídeo tem a cabeça no campo negativo da linha y e a parte traseira na porção positiva da abscissa, ambas afastadas do ponto zero. No meio do círculo feito em rosa, a figura sobre o ponto zero possui traços em todos os quadrantes. O maior deles - que a corta - se destaca por ir dos pontos mais negativos do eixo $x$ e y aos pontos mais positivos das coordenadas cartesianas, se apresentando na mesma fórmula dicotômica identificada nos casos anteriores. 


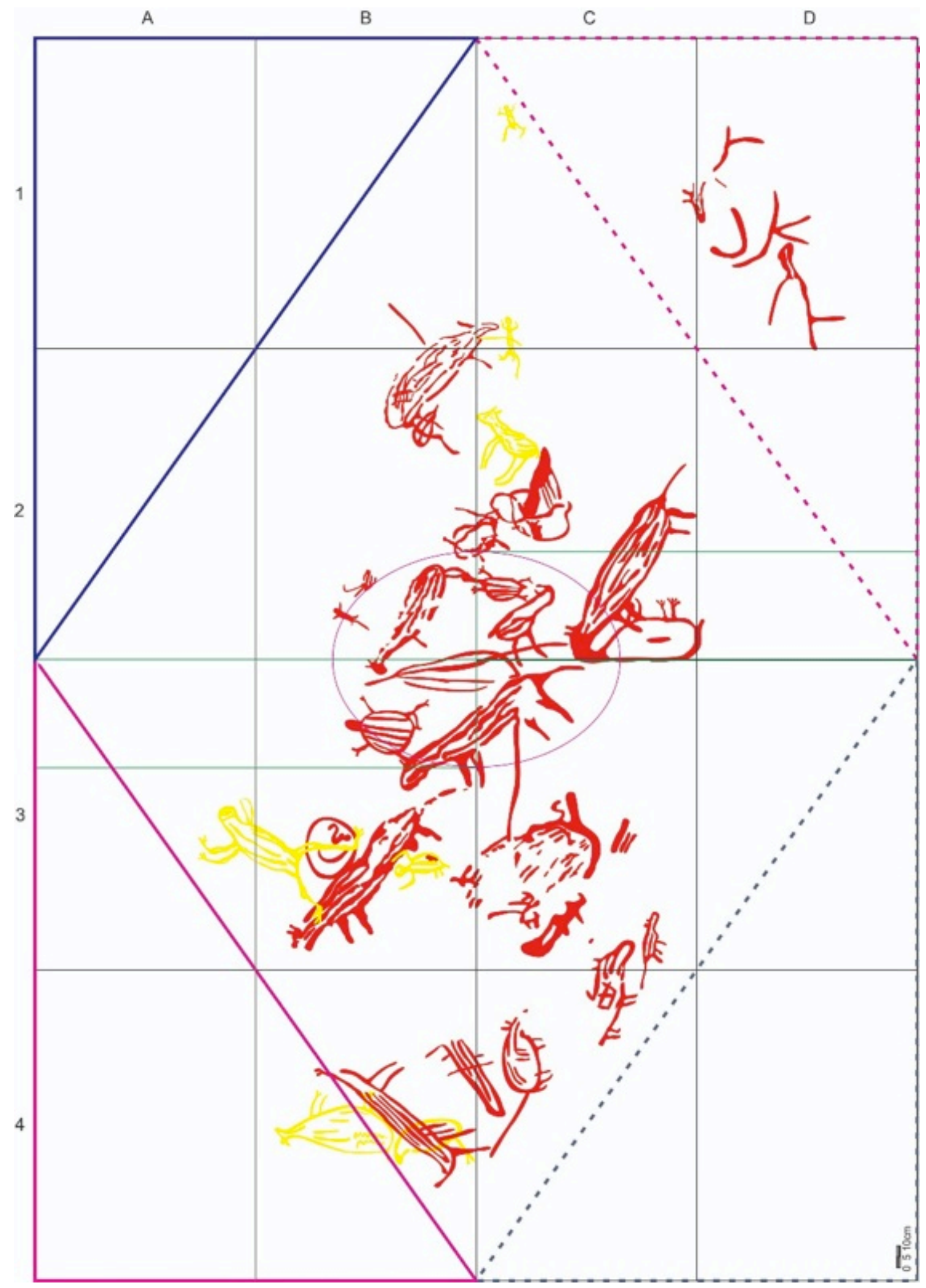

Figura 12: Estrutura metodológica de análise dos grafismos. Greco, 2018. 
É possível considerar que as pinturas não foram feitas juntas, mas em momentos diferentes, em relações diacrônicas. Contudo, isso não vai de encontro à análise do painel como produto de relações sincrônicas, uma vez que "[...] a ordem de sucessão cronológica se reabsorve numa estrutura matriz atemporal cuja forma é, efetivamente, constante; e os deslocamentos de funções são mais do que uma de suas formas de substituição" (Lévi-Strauss, 1993: 144). A cada outra pintura, a estrutura é reforçada, mesmo em um processo que não exclui a historicidade e dinâmica sociais.

Além disso, cumpre ressaltar que tal análise, de maneira alguma, pacifica as relações sociais ou diminui o impacto dos conflitos intra e entre grupos. Fazer isso seria no mínimo um equívoco, uma vez que são nessas relações de diversidades que, acordos, opressões, manutenções e identidades se mantém. Lévi-Strauss, a esse respeito, destaca que: "Existem nas sociedades humanas, simultaneamente em elaboração, forças trabalhando em direção opostas: umas tendem à manutenção, e mesmo à acentuação dos particularismos; as outras agem no sentido da convergência e da afinidade" (Lévi-Strauss, 1993: 331).

Outro ponto que cumpre destacar é que a análise estruturalista também não suprime a ação de indivíduos, apenas possui foco de pesquisa que é maior que eles, estando centrado no coletivo. Todavia, a diferença formal, a escolha entre as funções disponíveis, a repetição de outras e o modo de ação são individuais, elaborações de uma pessoa. Pessoa esta que não se encontra isolada no mundo, mas intricadamente em uma sociedade, que é o seu círculo cultural, ou seja, a sociedade é a matriz de significação dela própria, dos indivíduos, assim como do mundo. É meramente metodológica a divisão entre indivíduo e grupo sócio-cultural.

Um dos pontos transversais a indivíduos e grupo é a língua. Talvez menos abstrata que uma discussão sobre modos de fazer, agir, (se) entender e ser, a língua ressalta a indissolubilidade entre indivíduo e grupo. É por meio da língua que o mundo é significado.

\section{Considerações}

Na pesquisa em arte rupestre, o quê e o como são possíveis de alcance, mas os porquês e para quê e/ou quem, provavelmente não. Contudo, mesmo que sobre caráter hipotético, fraco por não ser passível de comprovação e averiguação, considera-se válido sublinhar a importância de agentes outros da natureza na organização do tempo de sociedades não-ocidentais (LéviStrauss, 1957, 1989). Os zoomorfos são bem mais que signos em forma de animais e, talvez, estivessem relacionados ao entendimento do tempo ou do espaço.

Em Jambreiro, apenas um zoomorfo em forma de peixe foi identificado, mas em Serra Negra, assim como em grande parte das pinturas identificadas em Minas Gerais, a associação entre cervídeos e peixes é recorrente, um marcador para a Tradição Planalto (Prous, 1992). Se listarmos características desses dois, considerando que suas formas fazem menção aos animais, ainda que indiretamente, é possível apontar algumas hipóteses (Quadro 01). 
Quadro 01: Hipóteses de trabalho:

\begin{tabular}{|l|l|}
\hline Terra & Água \\
\hline Sangue Quente & Sangue Frio \\
\hline Carne Vermelha & Carne Branca \\
\hline Dia & Noite \\
\hline Acima da Terra & Abaixo do Nível da Terra \\
\hline Tempo de Caça & Tempo de Pesca \\
\hline Período de Gestação e Amamentação & Período de Desova \\
\hline
\end{tabular}

A relação com animais outros não se dá apenas pela via da caça, ela pode ser por temas diversos, que podem envolver, por exemplo, apenas questões de ordem simbólicas, ontológicas e/ou cosmológicas. Com isso, não se pretende afirmar que os autores das pinturas caçavam tais animais, mas como dito anteriormente, os zoomorfos são apenas grafismos em forma de animais, o verdadeiro significado poderia ser ou estar próximo a uma das questões listadas acima.

Não obstante, cabe destacar que o que se pretende com as considerações é apenas enfatizar a complexidade e diversidade que envolve a interpretação da arte, e não o seu exercício, o que seria um equívoco.

Contudo, é na ênfase de seu caráter enquanto construção humana material e imaterial que modifica o mundo (real e imaginário), assim como a humanidade nele, que a paisagem se constitui enquanto conceito importante à discussão teórica em arte rupestre. Não somente aspectos ambientais a influencia, seja na produção ou preservação, mas é nas características que se dão sob o conceito de paisagem que residem fatores de significação e, por isso, (modos de) manutenção, produção e preservação da arte podem ser mais amplamente entendidos.

A análise de um painel rupestre é um recorte metodológico. As relações sociais que o constituíram vazavam as formas na parede e percorriam as serras, nos caminhos e visadas: na paisagem. Por isso, se ampliada a escala, é possível encontrar relações próximas, uma vez que se entende que esse caminho de fluídos de significação se davam e se dão em via dupla, das pinturas ao mundo e do mundo envolvente às pinturas. É aqui onde se dão nossas hipóteses de trabalho. Mais que traços de tinta, as pinturas são formas e conteúdos simbólicos, preenchidos por esse movimento perceptível, não só visual, porque ela não é unicamente aquilo que se vê, mas aquilo que se entende e sente.

A arte abrange todos os sentidos humanos. Ela é uma construção total, produto de um modo de trabalho. Não só visual, mas em relações e atividades que envolvem olfato, tato, paladar e audição, como discutimos anteriormente, a arte ultrapassa a pintura; ela é maior que ela e não 
se prende no teto, mas transpassa os humanos, nessas linhas que percorrem o mundo e o formam como uma teia de significados.

Essa teia é a paisagem, os pontos de encontro das linhas constituem os lugares. Os traços das pinturas de Jambreiro são conteúdo desses mesmos fios de mundo. Mundo que é estrutural, sendo humano. Mundo que é movimento, sendo estrutura.

\section{Referências}

ACUTO, F. A. 1999. Paisajes cambiantes: La dominación Inka em El Valle Calchaquí Norte (Argentina). Revista do Museu de Arqueologia e Etnologia, MAE/USP, Anais da I Reunião Internacional de Teoria Arqueológica na América do Sul, Suplemento 03, pp.143-160.

ANCHUETZ, K.F; WILSHUSEN, R. H.; SCHEICK, C. 2001. An Archaeology of Landscapes: Perspectives and Directions. Journal of Archaeological Research, 09 (02), pp. 157-211.

COSGROVE, D. 1984.Social formation and symbolic landscape. London: Croom Helm.

FAGUNDES, M. 2013. O Projeto Arqueológico Alto Jequitinhonha (PAAJ) e a Área Arqueológica De Serra Negra, Alto Araçuaí, Minas Gerais - Aspectos Gerais. Revista Espinhaço, v. 2, n.2, pp. 68-95.

FAGUNDES, M. 2016. O Projeto Arqueológico Alto Jequitinhonha? Sítios Arqueológicos, Cultura Material e Cronologias para Compreensão das Ocupações Indígenas Holocênicas no Alto Vale do Rio Araçuaí, Minas Gerais - Brasil. Vozes dos Vales, v. 10, pp. 01-25.

ISNARDIS, A. 2004. Lapa, Parede, Painel: distribuição geográfica das unidades estilísticas de grafismos rupestres do vale do rio Peruaçu e suas relações diacrônicas (Alto-Médio São Francisco, Norte de Minas Gerais). Dissertação (Mestrado em Arqueologia). Programa de Pós-Graduação em Arqueologia do Museu de Arqueologia e Etnologia da Universidade de São Paulo, São Paulo.

KNEGT, L. M. P. 2015.Indicadores da paisagem para a ocorrência de sítios arqueológicos na Área Arqueológica de Serra Negra, face leste do Espinhaço. Dissertação (Mestrado em Geografia). Programa de Pós-Graduação em Geografia e Análise Ambiental do Instituto de Geociências da Universidade Federal de Minas Gerais, Belo Horizonte.

MAUSS, M. 1979.Sociologia y Antropologia, 4a ed. Traduzido por MARTIN-RETORTILLO, T. R. Madrid: Editorial Tecnos, S. A.

LÉVI-STRAUSS, C. 1957. Tristes trópicos. Tradução de Wilson Martins. São Paulo: Editora Anhembi Ltda.

LÉVI-STRAUSS, C. 1983. O olhar distanciado. Tradução de Carmen de Carvalho. Lisboa: Edições 70.

LÉVI-STRAUSS, C. 1985. A Oleira Ciumenta. Tradução de Beatriz Perrone-Moisés. São Paulo: Editora Brasiliense S.A. 
LÉVI-STRAUSS, C. 1989. O pensamento selvagem. Tradução de Tânia Pellegrini. Campinas: Papirus. LÉVI-STRAUSS, C. 1993. Antropologia Estrutural Dois, 40 ed. Tradução de Maria do Carmo Pandolfo. Rio de Janeiro: Tempo Brasileiro.

PROUS, A. 1992. Arqueologia Brasileira. Brasília: Editora da UNB.

SCHLANGER, S. 1992. Recognizing persistent places in Anasazi settlement systems. IN: ROSSIGNOL \& WANDSNIDER. Space, time, and archaeological landscapes. New York and London, Plenum Press, pp. 91-112.

TRONCOSO, A. M. 2001. Espacio y Poder. Boletín de la Sociedad Chilena de Arqueología, n. 32, pp.10-23.

ZVELEBIL, M. 1997. Hunter-gatherer ritual landscapes: spatial organization, social structure and ideology among hunter-gatherers of northern Europe and western Siberia. Analeca Praehistorica Leudesia, 29, pp. 33-50. 